\title{
Erratum to: Toxicity of Electronic Waste Leachates to Daphnia magna: Screening and Toxicity Identification Evaluation of Different Products, Components, and Materials
}

\author{
Delilah Lithner • Maja Halling • Göran Dave
}

Published online: 27 March 2012

(C) Springer Science+Business Media, LLC 2012

\section{Erratum to: Arch Environ Contam Toxicol DOI 10.1007/s00244-011-9729-0}

The original version of this article unfortunately contained a mistake. The positions for Figures 1 and 2 were inter- changed. The figure captions were positioned correctly but not their associated figures. The correct positions are given below.
Fig. 1 Photos of the eight most toxic components from discarded electronic products and $48 \mathrm{~h} \mathrm{EC}_{50} \mathrm{~s}$ for D. magna (replicated leachates)

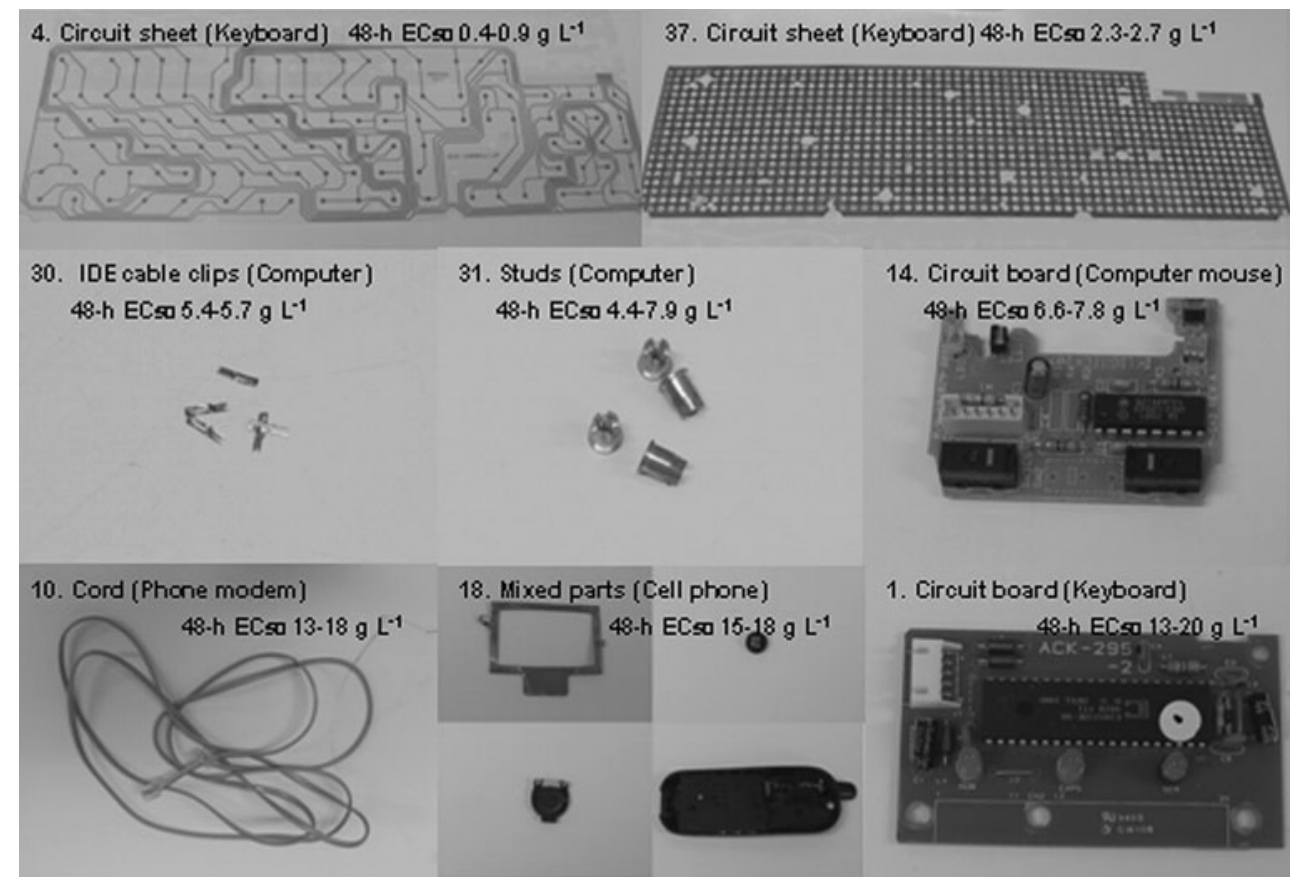

The online version of the original article can be found under doi:10.1007/s00244-011-9729-0.

D. Lithner $(\varangle) \cdot$ M. Halling $\cdot$ G. Dave

Department of Plant and Environmental Sciences,

University of Gothenburg, SE-405 30 Göteborg, Sweden

e-mail: delilah.lithner@gmail.com 


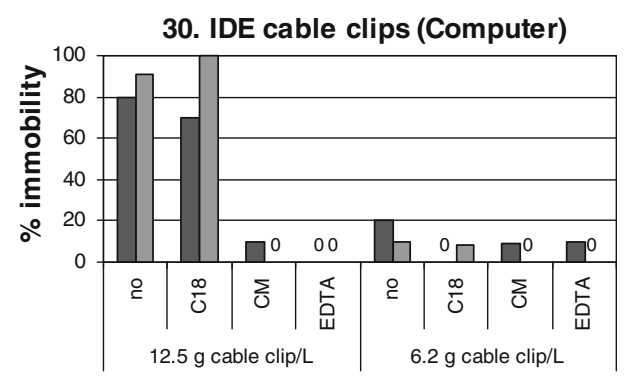

TIE manipulation

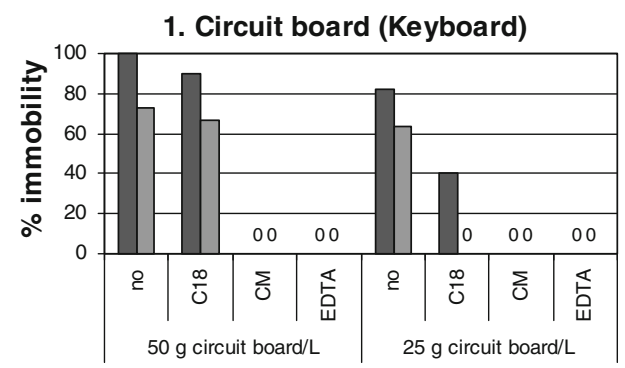

TIE manipulation

14. Circuit board (Computer mouse)

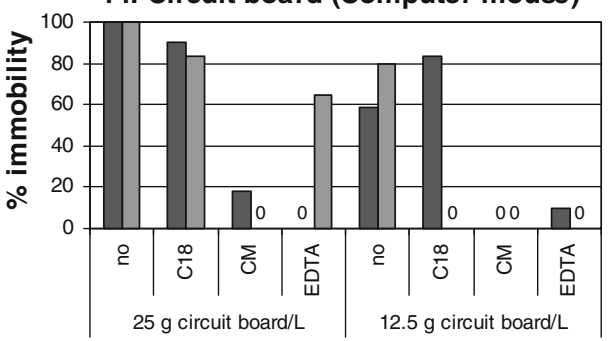

TIE manipulation

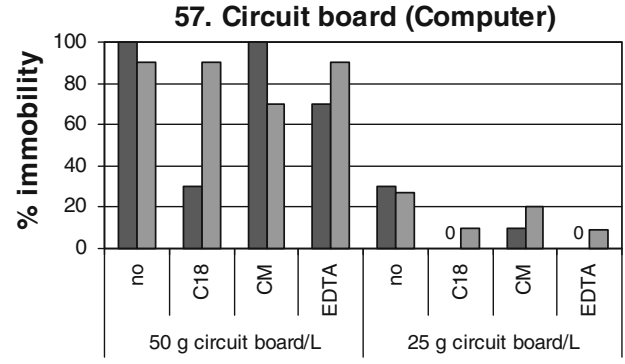

TIE manipulation

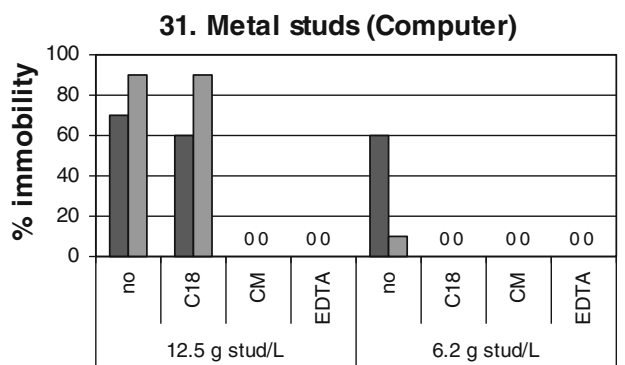

TIE manipulation

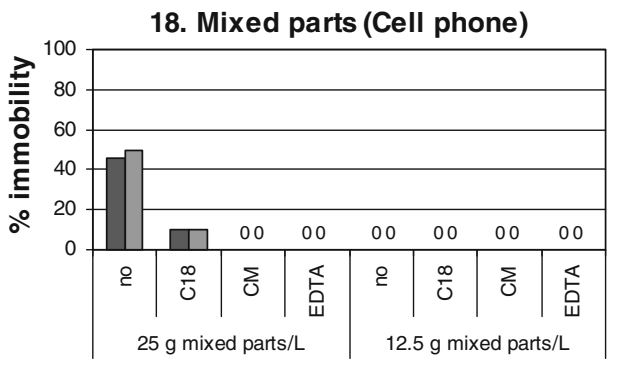

TIE manipulation

37. Circuit sheet (Keyboard)

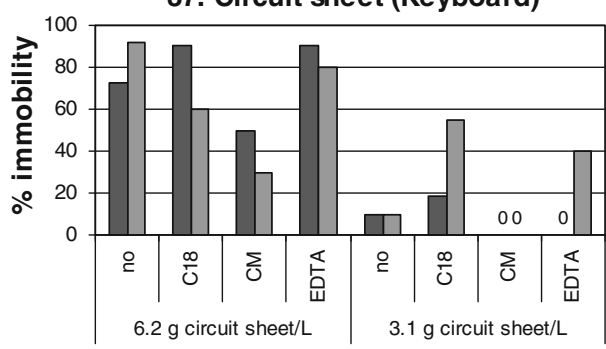

TIE manipulation

4. Circuit sheet (Keyboard)

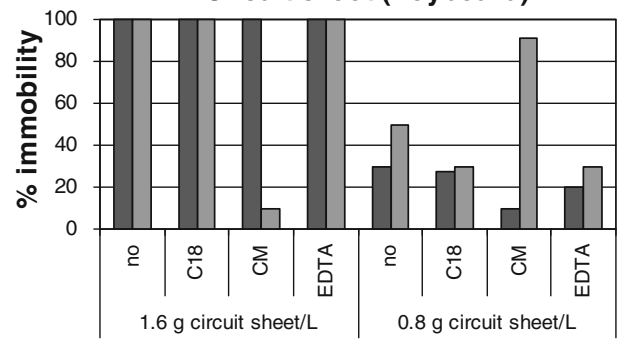

TIE manipulation

$\square$ Repl. 1 ๑ Repl. 2

Fig. 2 TIE on leachates from two metal (no. 30 and 31) and six mixed-material electronic waste samples. Manipulations include filtrations through $\mathrm{C} 18$ resin (removing nonpolar organics), filtrations through $\mathrm{CM}$ resin (removing cations), and EDTA addition (metal complexation), respectively. Immobility (\%) of D. magna after $24 \mathrm{~h}$ exposure is presented for leachates with and without manipulations 